\title{
Maxacalcitol ameliorates tubulointerstitial fibrosis in obstructed kidneys by recruiting PPM1A/VDR complex to $\mathrm{pSmad} 3$
}

\author{
Kazunori Inoue ${ }^{1}$, Isao Matsui ${ }^{1}$, Takayuki Hamano ${ }^{2}$, Naohiko Fujii ${ }^{3}$, Akihiro Shimomura ${ }^{1}$, Chikako Nakano ${ }^{1}$, \\ Yasuo Kusunoki ${ }^{1}$, Yoshitsugu Takabatake ${ }^{1}$, Michinori Hirata ${ }^{4}$, Akira Nishiyama ${ }^{5}$, Yoshiharu Tsubakihara², \\ Yoshitaka Isaka' and Hiromi Rakugi ${ }^{1}$
}

Tubulointerstitial fibrosis (TIF) is one of the major problems in nephrology because satisfactory therapeutic strategies have not been established. Here, we demonstrate that maxacalcitol (22-oxacalcitriol (OCT)), an analog of active vitamin D, protects the kidney from TIF by suppressing the autoinduction of transforming growth factor- $\beta 1$ (TGF- $\beta 1$ ). OCT suppressed the tubular injury index, interstitial volume index, collagen I positive area, and mRNA levels of extracellular matrix genes in unilateral ureteral-obstructed kidneys in rats. Although the renoprotective mechanism of active vitamin $D$ in previous studies has been mainly attributed to the suppression of renin, OCT did not affect renal levels of renin or angiotensin II. We found that TGF- $\beta 1$ itself induces its expression in a phospho-Smad3 (pSmad3)-dependent manner, and that OCT ameliorated TIF by abrogating this 'autoinduction'. Under the stimulation of TGF- $\beta 1$, pSmad3 bound to the proximal promoter region of the TGF- $\beta 1$ gene. Both OCT and SIS3, a Smad3 inhibitor, abrogated the binding of pSmad3 to the promoter and consequently attenuated the autoinduction. TGF- $\beta 1$ increased both the nuclear levels of protein phosphatase $\mathrm{Mg}^{2+} / \mathrm{Mn}^{2+}$-dependent 1A (PPM1A), a pSmad3 phosphatase, and the interaction levels between the vitamin $\mathrm{D}$ receptor (VDR) and PPM1A. In the absence of OCT, however, the interaction between pSmad3 and PPM1A was weak; therefore, it was insufficient to dephosphorylate pSmad3. The PPM1A/VDR complex was recruited to pSmad3 in the presence of both TGF- $\beta 1$ and OCT. This recruitment promoted the dephosphorylation of pSmad3 and attenuated the pSmad3-dependent production of TGF- $\beta 1$. Our findings provide a novel approach to inhibit the TGF- $\beta$ pathway in fibrotic diseases.

Laboratory Investigation (2012) 92, 1686-1697; doi:10.1038/labinvest.2012.107; published online 27 August 2012

KEYWORDS: maxacalcitol (22-oxacalcitriol (OCT); protein phosphatase $\mathrm{Mg}^{2+} / \mathrm{Mn}^{2+}$-dependent $1 \mathrm{~A}$ (PPM1A); Smad3; TGF- $\beta 1$; vitamin D

Tubulointerstitial fibrosis (TIF) is the final common pathway for most forms of progressive kidney diseases. ${ }^{1-3}$ Numerous studies revealed that two major signaling pathways, the renin-angiotensin system (RAS) and the transforming growth factor- $\beta 1$ (TGF- $\beta 1$ )/Smad system, have important roles in the pathogenesis of TIF. $^{3-6}$ However, because satisfactory therapeutic strategies have not been established, TIF remains one of the major problems in nephrology.
One of the candidates that protect the kidney from TIF is active vitamin $\mathrm{D}$ because it is a negative regulator of renin. ${ }^{7,8}$ Several lines of studies revealed the renin-suppressive effect of 1,25-dihydroxyvitamin $\mathrm{D}\left[1,25(\mathrm{OH})_{2} \mathrm{D}\right] \cdot .^{9-12}$ In addition to $1,25(\mathrm{OH})_{2} \mathrm{D}$, a less-calcemic analog, paricalcitol, has been revealed to suppress renin in the kidney. ${ }^{13}$ These findings provide a rationale for active vitamin $\mathrm{D}$ therapy in renal diseases with high local renin.

\footnotetext{
${ }^{1}$ Department of Geriatric Medicine and Nephrology, Osaka University Graduate School of Medicine, 2-2 Yamada-oka, Suita, Japan; ${ }^{2}$ Department of Comprehensive Kidney Disease Research, Osaka University Graduate School of Medicine, 2-2 Yamada-oka, Suita, Japan; ${ }^{3}$ Department of Internal Medicine, Hyogo Prefectural Nishinomiya Hospital, 13-9 Rokutanji-cho, Nishinomiya, Japan; ${ }^{4}$ Product Research Department, Chugai Pharmaceutical, 1-135 Komakado, Gotemba, Japan and ${ }^{5}$ Department of Pharmacology, Kagawa University School of Medicine, 1750-1 Ikenobe, Miki-cho, Japan

Correspondence: Dr T Hamano, MD, PhD, Department of Geriatric Medicine and Nephrology, Osaka University Graduate School of Medicine, 2-2 Yamadaoka, Suita, Osaka 565-0871, Japan.

E-mail: hamatea@medone.med.osaka-u.ac.jp

Received 2 January 2012; revised 1 June 2012; accepted 2 July 2012
} 
TGF- $\beta 1$ is widely recognized as a strong inducer of fibrosis in renal structures. ${ }^{14,15}$ Binding of TGF- $\beta 1$ to its receptors induces the phosphorylation of $\operatorname{Smad} 2 / 3$, which allows them to regulate the transcription of target genes. ${ }^{16}$ When TGF- $\beta 1$ stimulation is terminated, Smad $2 / 3$ becomes dephosphorylated. ${ }^{16}$ Lin et al revealed that protein phosphatase $\mathrm{Mg}^{2+} / \mathrm{Mn}^{2+}$-dependent 1A (PPM1A) is responsible for the dephosphorylation of Smad2/3. ${ }^{17}$ Because PPM1A inhibits the TGF- $\beta 1 /$ Smad pathway, activation of PPM1A seems to be an attractive strategy for treating fibrotic diseases.

Maxacalcitol (also known as 22-oxacalcitriol (OCT)) is one of the less calcemic analogs of active vitamin D. ${ }^{18}$ We previously showed that OCT ameliorates puromycin aminonucleoside-induced nephrosis in rats. ${ }^{19}$ However, it is currently unknown whether OCT ameliorates TIF or not. The effect of OCT on the regulation of renin and TGF- $\beta 1 /$ Smad pathway also remains obscure.

Here, we investigate the potential of OCT to suppress TIF in a well-established model, unilateral ureteral obstruction (UUO). Our findings provide a novel rationale for active vitamin $\mathrm{D}$ therapy in fibrotic kidney diseases.

\section{MATERIALS AND METHODS}

\section{Animals}

Six-week-old male Sprague-Dawley rats were purchased from Japan SLC (Hamamatsu, Japan). The rats were handled in a humane manner in accordance with the guidelines of the Animal Committee of Osaka University. We divided rats randomly into four groups: (a) sham + vehicle, (b) sham + OCT, (c) UUO + vehicle, and (d) UUO + OCT. UUO was performed under pentobarbital anesthesia in which a midline incision was made and the left ureter was tied off at two points. OCT provided from Chugai Pharmaceutical (Tokyo, Japan) at a dose of $0.5 \mu \mathrm{g} / \mathrm{kg} \cdot \mathrm{BW}$ or vehicle was subcutaneously injected twice a day from 3 days before the surgical operation until killing at 3 days after the operation. Rats in Figure 3a received a single injection of OCT or $1,25(\mathrm{OH})_{2} \mathrm{D}$ at a dose of $0.5 \mu \mathrm{g} / \mathrm{kg} \cdot \mathrm{BW}$. All rats, except for histological analyses, were killed by decapitation. Renal angiotensin II levels were measured by RIA, as described previously in detail. ${ }^{20}$

\section{Histology and Immunohistochemistry}

Kidney sections were stained with Periodic acid Schiff (PAS) by standard procedure. Indirect immunohistochemical staining for collagen I (ab34710, Abcam, Cambridge Science Park, UK) was carried out as described previously. ${ }^{21,22}$ The dilution rate of the primary antibody was 1:200. To evaluate tubular injury and interstitial volume, we performed morphometric analyses in PAS-stained sections. ${ }^{23}$ Briefly, digital images of cortical high-power magnification $(\times 400)$ were taken by BZ-9000 microscopy (KEYENCE, Osaka, Japan). Then, a grid that contained $120(12 \times 10)$ sampling points was superimposed on the images. The number of grid points overlying atrophic or necrotic tubular cells (tubular injury index) or interstitial space (interstitial volume index) were counted and expressed as a percentage of all sampling points. The percentage of the immune-positive area for collagen I was calculated using a digital image-analyzing software (Image 1.41, U. S. National Institutes of Health, Bethesda, MD, USA, http://rsb.info.nih.gov/ij/). For each kidney, 30 randomly selected fields were analyzed.

\section{Quantitative Reverse Transcription-PCR}

In order to quantify the expression levels of mRNA, real-time SYBR-Green PCR analysis was performed using ABI PRISM 7900HT (Applied Biosystems, Carlsbad, CA, USA). The primer sets are shown in Table 1 .

\section{Western Blot Analysis}

Antibodies against specific molecules were obtained as follows: $\alpha$-smooth muscle actin ( $\alpha$-SMA) (A2547 (clone 1A4), Sigma-Aldrich, St Louis, MO, USA); renin (the kind gift from Dr Tadashi Inagami, Vanderbilt University School of Medicine, TN, USA); TGF- $\beta 1$ (G1221, Promega, Madison, WI, USA); Smad2/3 (sc-133098, Santa Cruz Biotechnology, Santa Cruz, CA, USA); Smad3 (No. 9523, Cell Signaling Technology, Danvers, MA, USA), phospho-Smad3 (pSmad3) (No. 9520, Cell Signaling Technology); vitamin D receptor (VDR) (sc-1008, Santa Cruz Biotechnology); PPM1A (ab76574 (clone EP1684Y), Abcam); lamin B1 (33-2000 (clone L-5), Zymed Laboratory, San Francisco, CA, USA); and $\beta$-actin (A5441 (clone AC-15), Sigma-Aldrich). Western blot analyses were carried out as described previously. ${ }^{24}$ The dilution rates of the primary antibodies were 1:10000 for $\beta$-actin, 1:2000 for $\alpha$-SMA and renin, 1:1000 for TGF- $\beta 1$, Smad3, pSmad3 and PPM1A, 1:500 for lamin B1, and 1:200 for Smad2/3 and VDR.

\section{Cell Culture}

NRK-52E cells were maintained in DMEM supplemented with 5\% FCS and $1 \times$ non-essential amino acids. For the evaluation of the antifibrotic effects of OCT, NRK-52E cells at $30 \%$ confluency in DMEM supplemented with $0.5 \%$ charcoal-stripped FCS were plated in culture dishes (Figures 5-7). In Figures $5-7 \mathrm{a}$, fibrosis was induced by TGF- $\beta 1$ at a dose of $1.0 \mathrm{ng} / \mathrm{ml}$ under the absence or presence of OCT at the indicated concentrations for $48 \mathrm{~h}$. In Figures $7 \mathrm{~b}-\mathrm{e}$, cells were stimulated with TGF- $\beta 1(1.0 \mathrm{ng} / \mathrm{ml})$ for $48 \mathrm{~h}$ in the absence or presence of SB431542 (Sigma-Aldrich) at a dose of $10 \mu \mathrm{M}$, or SIS3 (Merck KGaA, Darmstadt, Germany) at a dose of $2.0 \mu \mathrm{m}$. After the incubation, samples were subjected to quantitative reverse transcription-PCR analyses or western blot analyses.

As4.1 cells were maintained in DMEM supplemented with $10 \%$ FCS. For the evaluation of the renin-suppressive effects of active vitamin D, As4.1 cells at 50\% confluency in DMEM supplemented with $0.3 \%$ charcoal-stripped FCS were plated in culture dishes (Figure 3b). As4.1 cells were treated with $1,25(\mathrm{OH})_{2} \mathrm{D}$, paricalcitol, or OCT at a concentration of 
$1.0 \times 10^{-8} \mathrm{M}$ for $24 \mathrm{~h}$. Messenger RNA levels of renin were assessed by quantitative reverse transcription-PCR analyses.

\section{Luciferase Assay}

Various fragments of the rat TGF- $\beta 1$ gene promoter (segment $\mathrm{A},-655$ to $-396 \mathrm{bp}$; segment $\mathrm{B},-388$ to $-210 \mathrm{bp}$; and segment $\mathrm{C},-174$ to $+49 \mathrm{bp}$ ) were cloned into a XhoI/BglIIcut pGL4.26 vector (Promega). Constructed vectors carrying various TGF- $\beta 1$ gene promoter segments were introduced into NRK-52E cells using Amaxa Nucleofector (Amaxa, Lonza, Basel, Switzerland). OCT at a dose of $1.0 \times 10^{-8} \mathrm{M}$, SIS3 at a dose of $2.0 \mu \mathrm{M}$, and/or TGF- $\beta 1$ at a dose of $3.0 \mathrm{ng} /$ $\mathrm{ml}$ were added to the media, where indicated. Firefly luciferase activities were measured using LB9507 luminometer (Berthold Technology, Wildbad, Germany). The firefly luciferase activities were normalized to protein concentrations of the lysates.

\section{Immunoprecipitation}

NRK-52E cells at 30\% confluency in DMEM supplemented with $0.5 \%$ charcoal-stripped FCS were treated for $24 \mathrm{~h}$ with TGF- $\beta 1$ at a dose of $1.0 \mathrm{ng} / \mathrm{ml}$, or OCT at a dose of $1.0 \times 10^{-8} \mathrm{M}$, or both. After these treatments, nuclear proteins were extracted. Extracted nuclear proteins were incubated with anti-Smad3 (Cell Signaling Technology), antipSmad3 (Cell Signaling Technology), anti-PPM1A (Abcam), or an anti-VDR antibody (Santa Cruz Biotechnology), followed by incubation with Protein G Sepharose. The dilution rates of the antibodies were 1:50. The precipitates were diluted in Laemmli buffer and subjected to western blot analyses using TrueBlot (eBioscience, San Diego, CA, USA) as a secondary antibody.

\section{Chromatin Immunoprecipitaion (ChIP) Assay}

A ChIP assay was carried out using a ChIP Assay Kit according to the manufacturer's instructions (Upstate Millipore, Billerica, MA, USA). NRK-52E cells treated with TGF- $\beta 1$ $(1.0 \mathrm{ng} / \mathrm{ml})$, OCT $\left(1.0 \times 10^{-8} \mathrm{M}\right)$, and/or SIS3 $(2.0 \mu \mathrm{M})$ for $24 \mathrm{~h}$ were analyzed. The primer sets are shown in Table 1.

\section{Statistical Analysis}

Statistical significance was evaluated by Dunnett's test or Student's $t$-test. Statistical significance was defined as $P<0.05$. All results are presented as means \pm s.d. All data were statistically analyzed using JMP 8.0.1J for Windows (SAS Institute, Cary, NC, USA).

\section{RESULTS}

\section{OCT Suppressed TIF in UUO Rats}

Using UUO rats on day 3, we examined whether OCT suppresses TIF. PAS-stained kidney sections in low-power and high-power magnification are shown in Figures 1a and b,

Table 1 Primer nucleotide sequences

\begin{tabular}{|c|c|c|}
\hline & Forward & Reverse \\
\hline Collagen I (rat) & $5^{\prime}$-CCAGCTGACCTTCCTGCGCC-3' & 5'-TCCGGTGTGACTCGTGCAGC-3' \\
\hline Fibronectin (rat) & $5^{\prime}-$ GAAAGGCAACCAGCAGAGTC-3' & $5^{\prime}-\mathrm{CTGGAGTCAAGCCAGACACA-3^{ \prime }}$ \\
\hline TGF- $\beta 1$ (rat) & 5'-TGCTTCAGCTCCACAGAGAA-3' & $5^{\prime}$-TGGTTGTAGAGGGCAAGGAC-3' \\
\hline Renin (mouse) & 5'-CATCTITGACACGGGTTCAG-3' & $5^{\prime}$-CACCCACAGTCACCGAGTC-3' \\
\hline Osteopontin (rat) & 5'-GTCATCCCAGTTGCCCAGCGT-3' & $5^{\prime}$-CCGACCGCTCCGCACTATCG-3' \\
\hline Tumor necrosis factor- $\alpha$ (TNF- $\alpha$ ) (rat) & 5'-AGTCCGGGCAGGTCTACTIT-3' & $5^{\prime}$-GGCCACTACTTCAGCGTCTC-3' \\
\hline GAPDH (rat) & 5'-TGCACCACCAACTGCTTA-3' & 5'-GGATGCAGGGATGATGTT-3' \\
\hline GAPDH (mouse) & 5'-AACTTGGCATTGTGGAAGG-3' & $5^{\prime}$-ACACATTGGGGGTAGGAACA-3' \\
\hline
\end{tabular}

All primers were designed according to the sequence of each gene deposited in the GenBank database.

Figure 1 OCT ameliorated TIF in UUO rats on day 3. Kidney sections were stained with (a and $\mathbf{b})$ PAS or (c) anti-collagen I antibody (Scale bars; $100 \mu \mathrm{M}$ ). PAS-stained sections are shown in (a) low-power magnification or (b) high-power magnification. Representative micrographs from different groups, (A) sham + vehicle, (B) sham + OCT, (C) UUO + vehicle, and (D) UUO + OCT, are shown. (d) Graphic presentations of (A) tubular injury index, (B) interstitial volume index, and (C) ratio of collagen I-positive area revealed that OCT reduced histological damage in the obstructed kidney. All results are presented as means \pm s.d. ( $n=6-8$ in each group: ${ }^{* *} P<0.001$, Dunnett's test). 
a

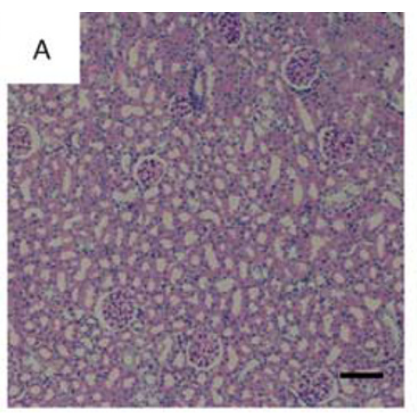

b

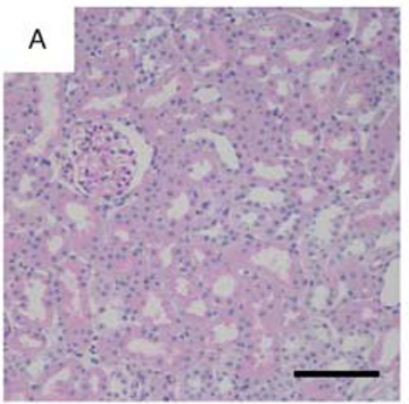

C $\mathrm{A}$

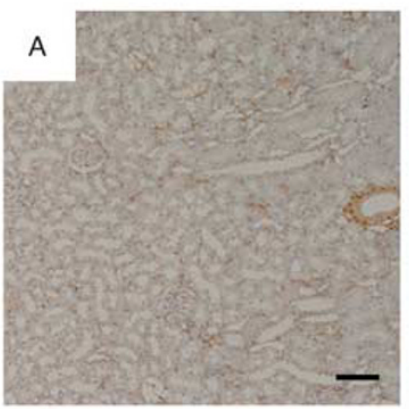

d

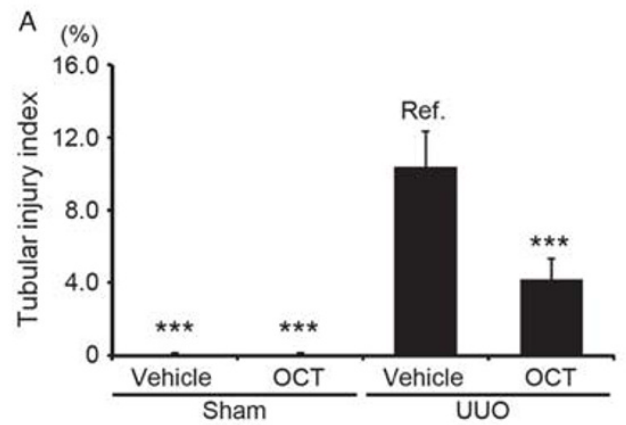

C $(\%)$
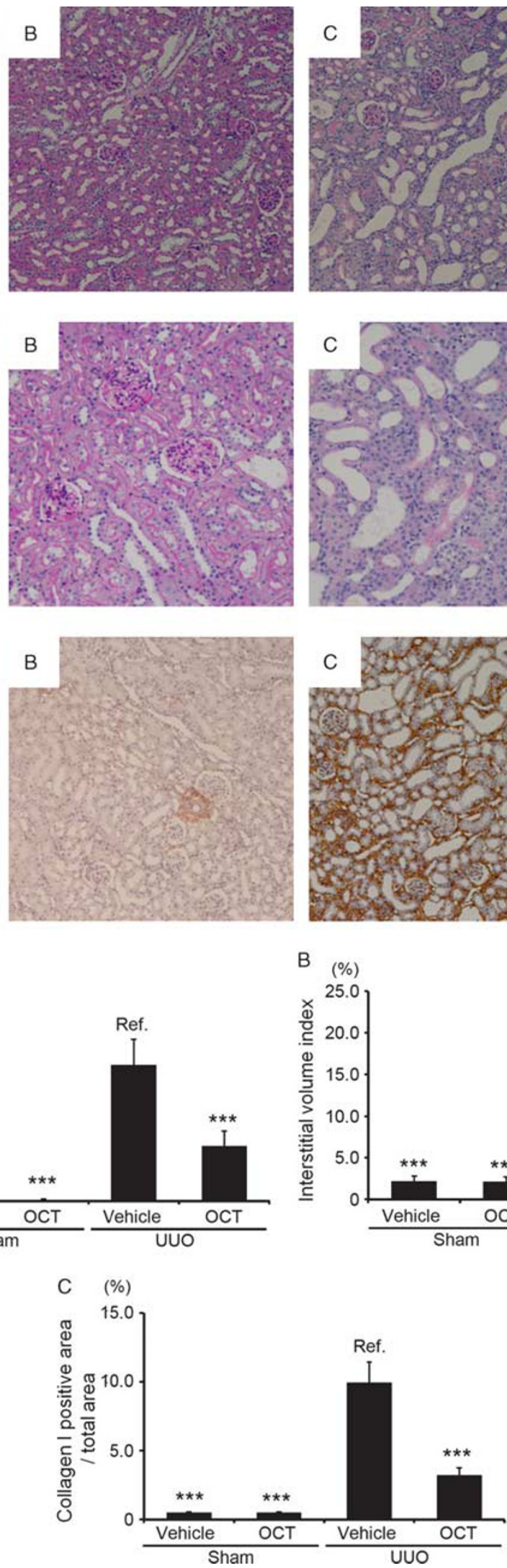
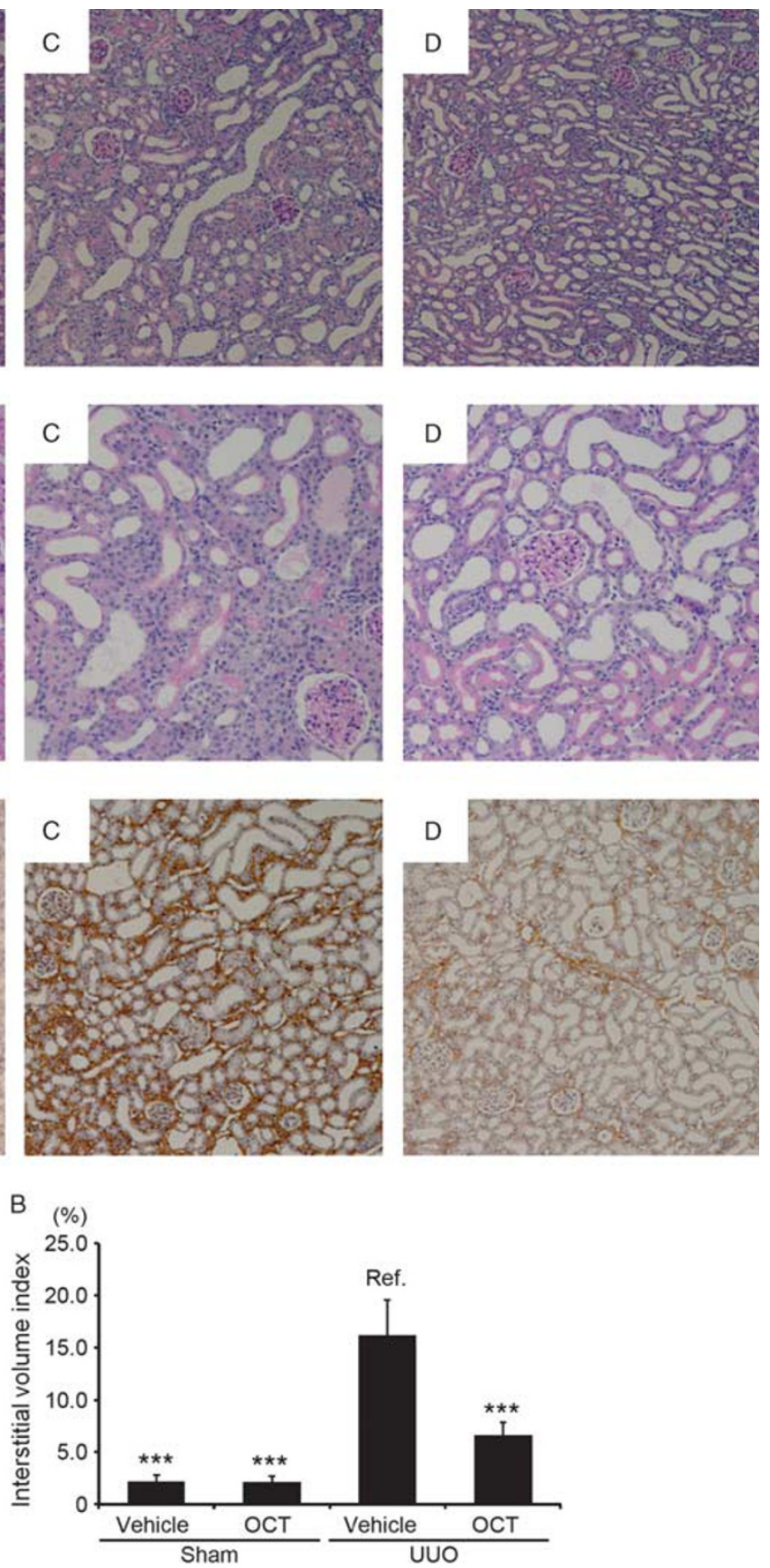
respectively. In comparison with the two sham-operated, the UUO + vehicle group had severe tubular damage and interstitial expansion (Figures 1a and b). This interstitial expansion was accompanied by an increased deposition of collagen I (Figure 1c). These pathological damages in the $\mathrm{UUO}+$ vehicle group were substantially attenuated in the UUO + OCT group (Figures 1a-cD). Morphometric analyses also demonstrated that OCT suppressed tubular damage (Figure 1dA), interstitial expansion (Figure 1dB), and collagen I-positive area (Figure $1 \mathrm{dC}$ ) in the obstructed
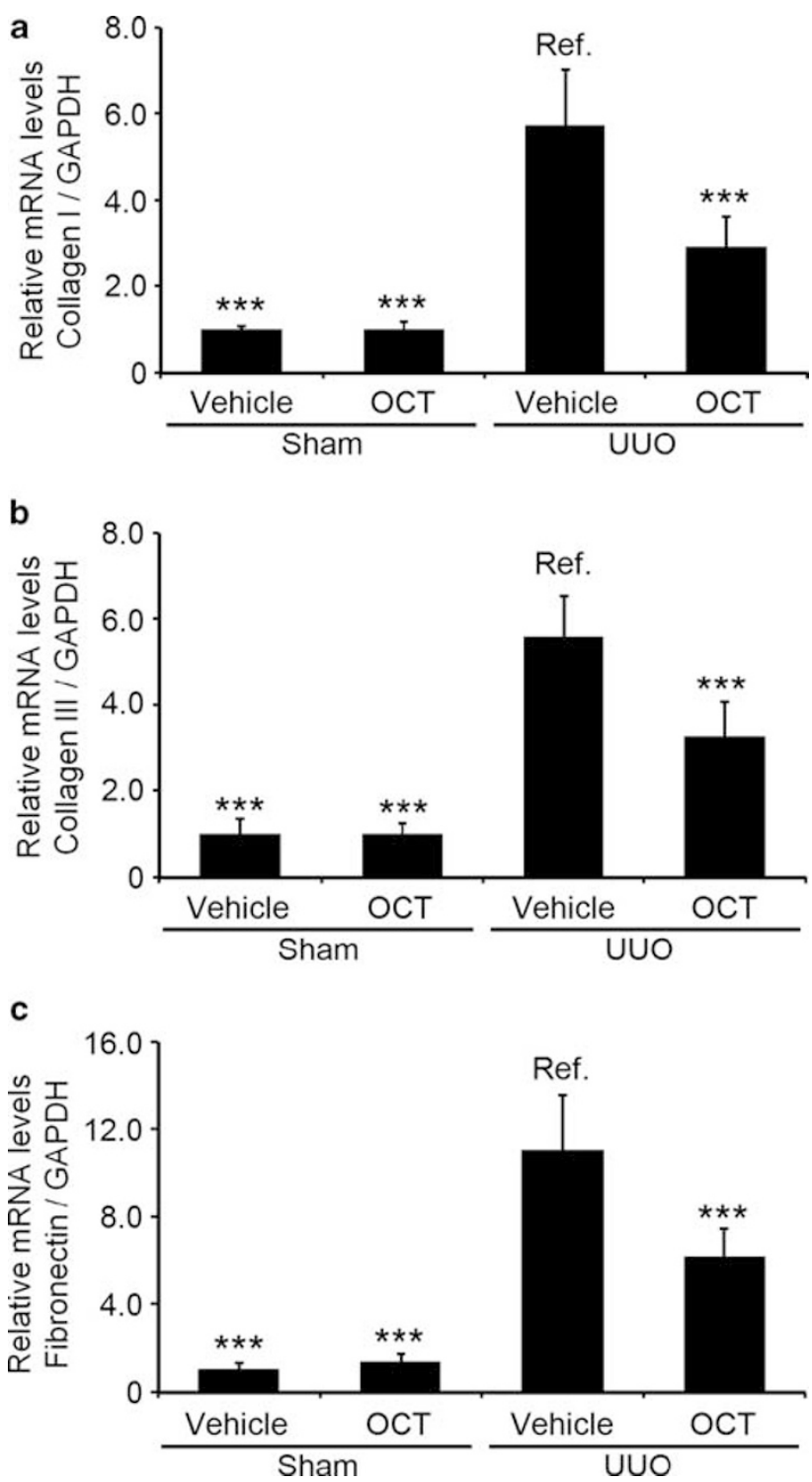

Figure 2 Extracellular matrix genes in the obstructed kidney were transcriptionally suppressed by OCT. Real-time PCR analyses demonstrated that renal mRNA levels for (a) collagen I, (b) collagen III, and (c) fibronectin, were upregulated in the $\mathrm{UUO}$ + vehicle group on day 3 in comparison with the two sham-operated groups. These upregulated extracellular matrix genes were suppressed in the UUO + OCT group. All results are presented as means \pm s.d. ( $n=5-8$ in each group: ${ }^{* * *} P<0.001$, Dunnett's test). kidney. Real-time PCR analyses showed that three major interstitial matrix components-collagen I (Figure 2a), collagen III (Figure 2b), and fibronectin (Figure 2c)-were transcriptionally upregulated in the UUO + vehicle group. OCT significantly suppressed these changes (Figure 2). Both histological analyses (Figure 1) and real-time PCR analyses (Figure 2) showed no obvious difference between the sham + vehicle group and the sham + OCT group. Under our experimental conditions, OCT slightly increased serum calcium in the UUO rats, whereas serum phosphate levels showed no difference (Table 2). Consistently, no calcium deposition was observed in the kidneys of the OCT-treated rats (data not shown).

\section{OCT Did Not Suppress Renal Renin and Angiotensin II}

Because the renoprotective mechanism of active vitamin D in previous studies has been mainly attributed to the suppression of renin, we analyzed whether OCT suppressed renin in the kidney. ${ }^{1,13,25-27}$ In Figure 3a, normal rats were subjected to a single injection of OCT or $1,25(\mathrm{OH})_{2} \mathrm{D}$ at a dose of $0.5 \mu \mathrm{g} / \mathrm{kg} \cdot \mathrm{BW}$. Although $1,25(\mathrm{OH})_{2} \mathrm{D}$ significantly suppressed renal renin mRNA at both 4 and $12 \mathrm{~h}$ after the injection, OCT did not affect the expression (Figure 3a). Using As4.1 cells, we confirmed that both $1,25(\mathrm{OH})_{2} \mathrm{D}$ and paricalcitol, but not OCT, suppressed mRNA levels of renin (Figure $3 \mathrm{~b}$ ). We further analyzed whether OCT suppressed renal RAS in UUO rats. Both vehicle-treatedand OCT-treated-UUO rats had comparable levels of renin mRNA (Figure 3c), renin protein (Figure 3d), and angiotensin II (Figure 3e) in the kidneys. These findings indicated that OCT ameliorated TIF without suppressing renal RAS.

\section{OCT Ameliorated TIF by Suppressing the TGF- $\beta 1 / \mathrm{Smad} 3$ Signaling Pathway}

As OCT had no effect on renal RAS, we then analyzed how OCT ameliorated TIF in the UUO rats. In comparison with the two sham-operated groups, the UUO + vehicle group on

Table 2 Serum calcium and phosphate levels among different groups

\begin{tabular}{|c|c|c|c|c|}
\hline \multirow[b]{2}{*}{ Parameters } & \multicolumn{2}{|c|}{ Sham } & \multicolumn{2}{|c|}{ UUO } \\
\hline & + Vehicle & $+\mathrm{OCT}$ & + Vehicle & $+\mathrm{OCT}$ \\
\hline $\begin{array}{l}\text { Calcium } \\
(\mathrm{mg} / \mathrm{dl})\end{array}$ & $10.08 \pm 0.11^{\text {Ref. }}$ & $10.24 \pm 0.33^{\mathrm{NS}}$ & $9.83 \pm 0.68^{\mathrm{NS}}$ & $10.72 \pm 0.78^{* * *}$ \\
\hline $\begin{array}{l}\text { Phosphate } \\
(\mathrm{mg} / \mathrm{dl})\end{array}$ & $9.00 \pm 0.66^{\text {Ref. }}$ & $8.96 \pm 0.72^{\mathrm{NS}}$ & $8.44 \pm 0.49^{\mathrm{NS}}$ & $8.51 \pm 0.50^{\mathrm{NS}}$ \\
\hline
\end{tabular}

Serum parameters of rats described in Figure 1 are summarized. All results are presented as means \pm s.d. Statistical significance was evaluated by Dunnett's test. Group (sham + vehicle) served as a reference. ( $n=5-8$ in each group: $\left.{ }^{* *} P<0.001\right)$. 
a

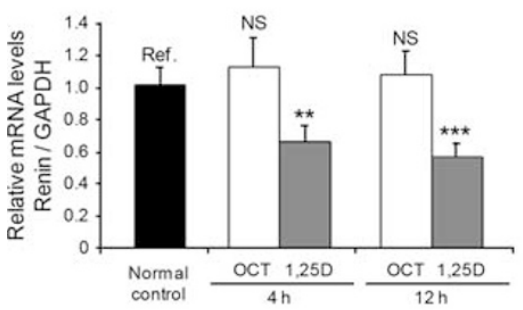

C

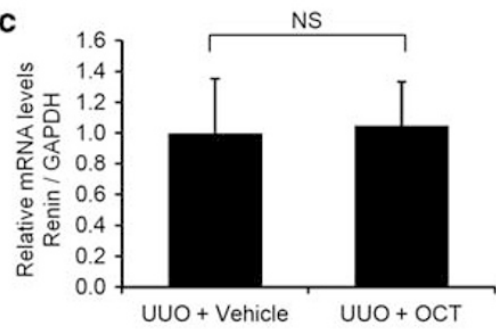

b

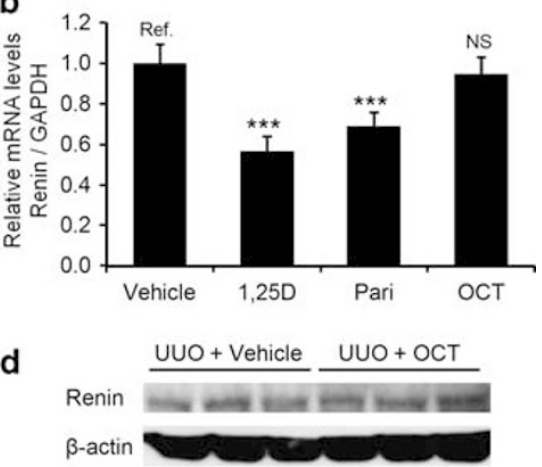

e

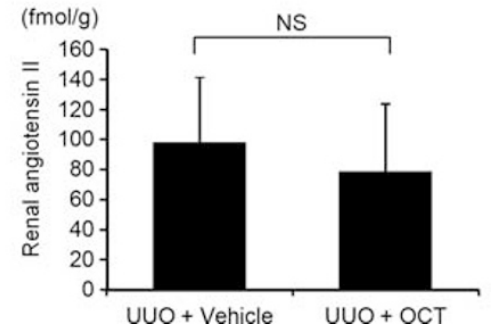

Figure 3 OCT did not suppress renal renin and angiotensin II. (a) Normal rats were subcutaneously injected with either $\mathrm{OCT}$ (white bars) or $1,25(\mathrm{OH})_{2} \mathrm{D}$ $(1,25 \mathrm{D})$ (gray bars) at a dose of $0.5 \mu \mathrm{g} / \mathrm{kg} \cdot \mathrm{BW}$. Four or twelve hours after the single injection of these compounds, rats were decapitated and the kidneys were subjected to real-time PCR analysis. Normal control rats (black bar) and OCT-injected rats had comparable levels of renal renin, whereas 1,25D-injected rats had significantly suppressed renin. ( $n=5-8$ in each group: ${ }^{* *} P<0.01 ;{ }^{* * *} P<0.001$, Dunnett's test). (b) As4.1 cells were treated with vehicle, 1 ,25D $\left(1.0 \times 10^{-8} \mathrm{M}\right)$, paricalcitol (Pari) $\left(1.0 \times 10^{-8} \mathrm{M}\right)$, or OCT $\left(1.0 \times 10^{-8} \mathrm{M}\right)$ for $24 \mathrm{~h}$. Messenger RNA levels for renin were analyzed by realtime PCR. ( $n=4$ in each group: ${ }^{* *} P<0.001$, Dunnett's test). (c-e) Both vehicle-treated- and OCT-treated-UUO rats had comparable levels of (c) renal renin mRNA, (d) renal renin protein, and (e) renal angiotensin II. ((c) $n=8$ and (e) $n=5$ in each group: Student's $t$-test).

day 3 had upregulated TGF- $\beta 1$ in the kidney both at mRNA and protein levels (Figure 4). As a consequence, the $\mathrm{UUO}+$ vehicle group had increased $\mathrm{pSmad} 3$ and $\alpha$-SMA (Figure 4b). These changes were substantially attenuated in the UUO + OCT group (Figure 4). In accordance with the results in vivo, OCT attenuated TGF- $\beta 1$-induced upregulation of $\alpha$-SMA, collagen I, III, fibronectin, and phosphorylation of Smad3 in cultured NRK-52E cells in a dose-dependent manner (Figures 5 and $6 \mathrm{a}-\mathrm{c}$ ). Because NRK-52E cells did not express mRNA for renin, these changes in vitro were not mediated by the suppression of renin (Figure 6d).

Figure 4 OCT suppressed the TGF- $\beta 1 /$ Smad signaling pathway in UUO rats. (a) Real-time PCR analysis showed that the renal mRNA level of TGF- $\beta 1$ in the UUO + vehicle group on day 3 was higher than those in the two sham-operated groups. OCT reduced the TGF- $\beta 1$ level in the obstructed kidney. All results are presented as means \pm s.d. $(n=5-8$ in each group: ${ }^{* *} P<0.001$, Dunnett's test). (b) The UUO + vehicle group had increased protein levels of TGF- $\beta 1$, pSmad3, and $\alpha$-SMA in the kidney. These changes were attenuated in the UUO + OCT group. Smad2/3 and coomassie brilliant blue (CBB)-stained acrylamide gel served as loading controls for western blot analysis. Three independent experiments showed similar results. a

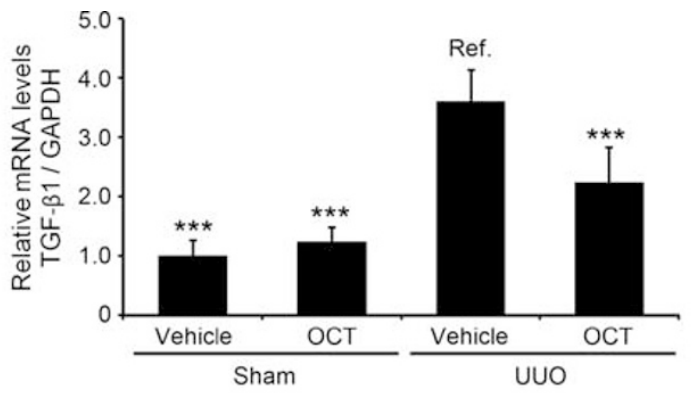

b

TGF- $\beta 1$

p-Smad 3

Smad 2/3

a-SMA

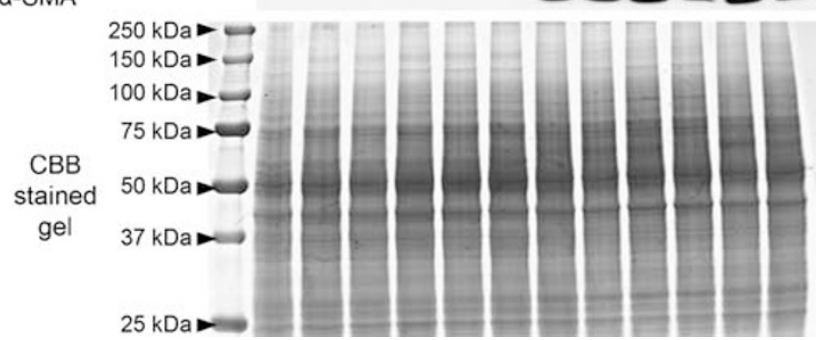




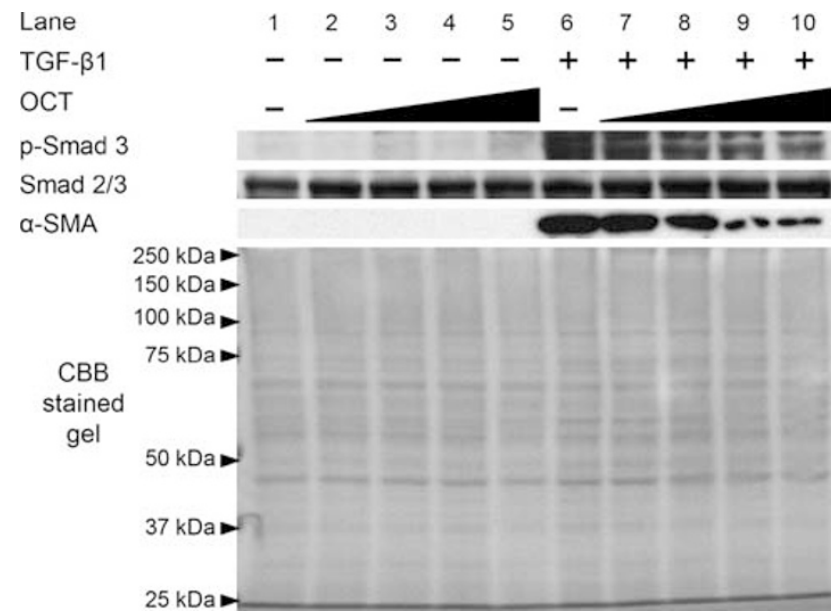

Figure 5 OCT suppressed the TGF- $\beta 1 /$ Smad signaling pathway in cultured NRK-52E cells. NRK-52E cells were treated with increasing doses of OCT in the absence (lanes 1-5) or presence (lanes $6-10$ ) of TGF- $\beta 1$ at a dose of $1.0 \mathrm{ng} / \mathrm{ml}$. The concentration of OCT was at $3.3 \times 10^{-11} \mathrm{M}$ (lanes 2 and 7), $1.0 \times 10^{-10} \mathrm{M}$ (lanes 3 and 8), $3.3 \times 10^{-10} \mathrm{M}$ (lanes 4 and 9), or $1.0 \times 10^{-9} \mathrm{M}$ (lanes 5 and 10). In lanes 1 and 6 , an ethanol vehicle instead of OCT was added. $\alpha$-SMA and pSmad3 levels in NRK-52E cells were upregulated by TGF- $\beta 1$. These changes were suppressed by OCT in a dose-dependent manner. Smad2/3 and coomassie brilliant blue (CBB)-stained acrylamide gel served as loading controls. Three independent experiments showed similar results.

\section{OCT Suppressed pSmad3-Dependent TGF- $\beta 1$ Production by Recruiting a Smad Phosphatase, PPM1A, to pSmad3} As the result shown in Figure 4 indicated that OCT suppressed the TGF- $\beta 1 / \mathrm{Smad} 3$ pathway by inhibiting the expression of TGF- $\beta 1$, we focused on the regulation of TGF- $\beta 1$ expression. We found that TGF- $\beta 1$ itself induces its expression in cultured NRK-52E cells (Figure 7a). OCT attenuated this autoinduction in a dose-dependent manner (Figure 7a). To examine whether the autoinduction of TGF- $\beta 1$ depends on the downstream Smad3 pathway, we investigated the effects of SB431542, a selective inhibitor of the TGF- $\beta 1$ type I receptor, and SIS3, a Smad3 inhibitor (Figures $7 \mathrm{~b}-\mathrm{e}$ ). After confirming that both SB431542 and SIS3 inhibit the phosphorylation of Smad3 (Figures $7 \mathrm{~b}$ and c), we found that both compounds attenuated the autoinduction (Figures $7 \mathrm{~d}$ and e). These findings indicated that TGF- $\beta 1$ induces itself in a pSmad3-dependent manner and that OCT suppresses the TGF- $\beta 1 / \mathrm{Smad} 3$ pathway by abrogating the autoinduction.

We searched the promoter of the TGF- $\beta 1$ gene for pSmad3-responsive elements. The DNA sequence of the TGF- $\beta 1$ gene promoter contained four putative Smad-binding elements (SBEs) (Figure 8aA arrowheads and Figure 8aB boxed CAGA motifs). We divided the promoter into three segments-A, B, and C (Figure 8a). Luciferase assays revealed that neither segment $\mathrm{A}$ nor $\mathrm{B}$, but segment $\mathrm{C}$ responded to both the stimulation of TGF- $\beta 1$ and the treatment of OCT or SIS3 (Figure 8b). To confirm that segment $\mathrm{C}$ was really the
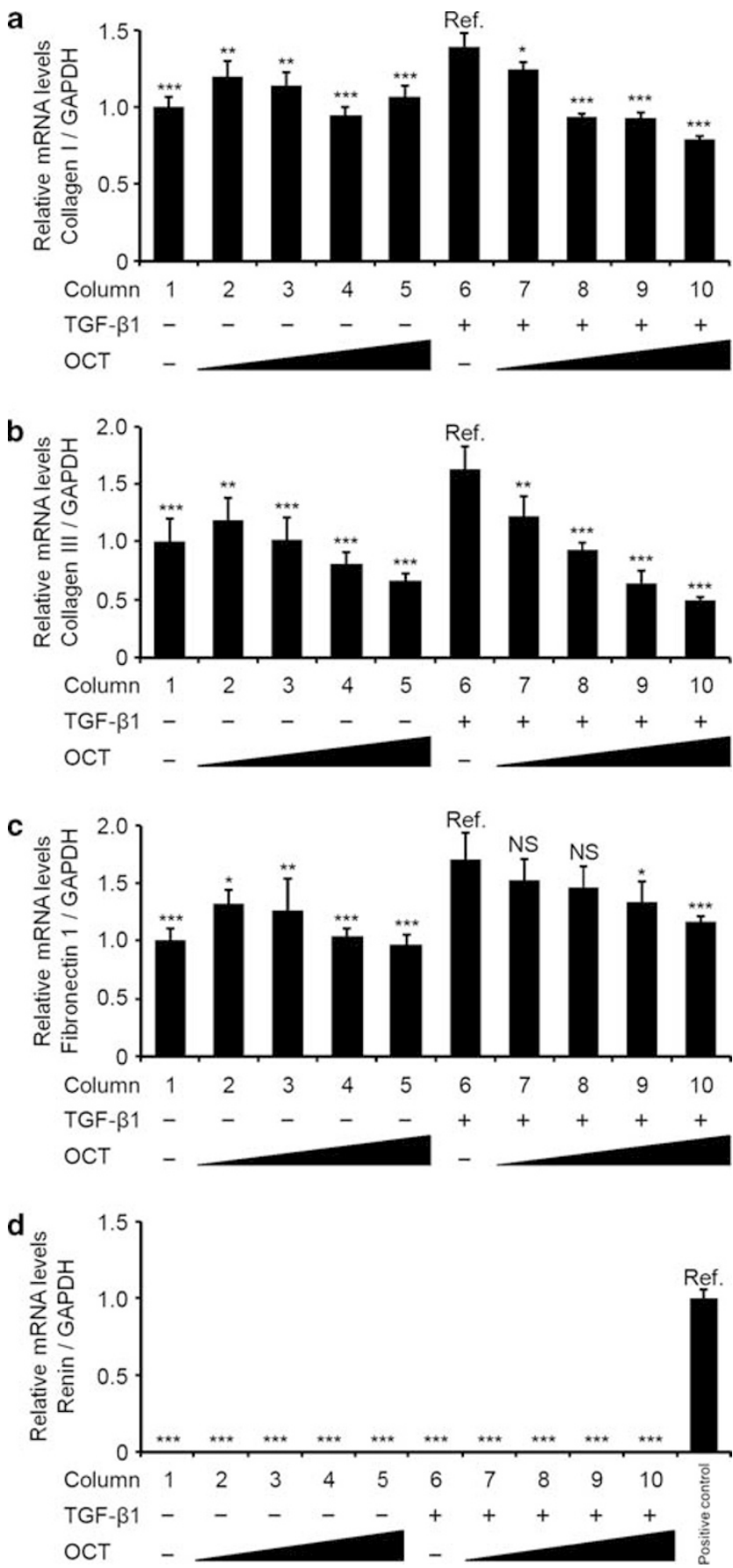

Figure 6 OCT suppressed the expression of extracellular matrix genes in cultured NRK-52E cells. (a-c) NRK-52E cells were treated with increasing doses of OCT in the absence (columns 1-5) or presence (columns $6-10$ ) of TGF- $\beta 1$ at a dose of $1.0 \mathrm{ng} / \mathrm{ml}$. The concentration of OCT was at $3.3 \times 10^{-11} \mathrm{M}$ (columns 2 and 7 ), $1.0 \times 10^{-10} \mathrm{M}$ (columns 3 and 8 ), $3.3 \times 10^{-10} \mathrm{M}$ (columns 4 and 9), or $1.0 \times 10^{-9} \mathrm{M}$ (columns 5 and 10). In columns 1 and 6 , an ethanol vehicle instead of OCT was added. Messenger RNA expression levels of (a) collagen I, (b) collagen III, and (c) fibronectin were analyzed by real-time PCR. OCT inhibited TGF- $\beta 1$-induced expression of collagen I, collagen III, and fibronectin. (d) NRK-52E cells did not express mRNA for renin. Normal rat kidney served as positive control. All results are presented as means \pm s.d. ( $n=4$ in each group: ${ }^{*} P<0.05 ;{ }^{*} P<0.01 ;{ }^{* *} P<0.001$, Dunnett's test). 
a
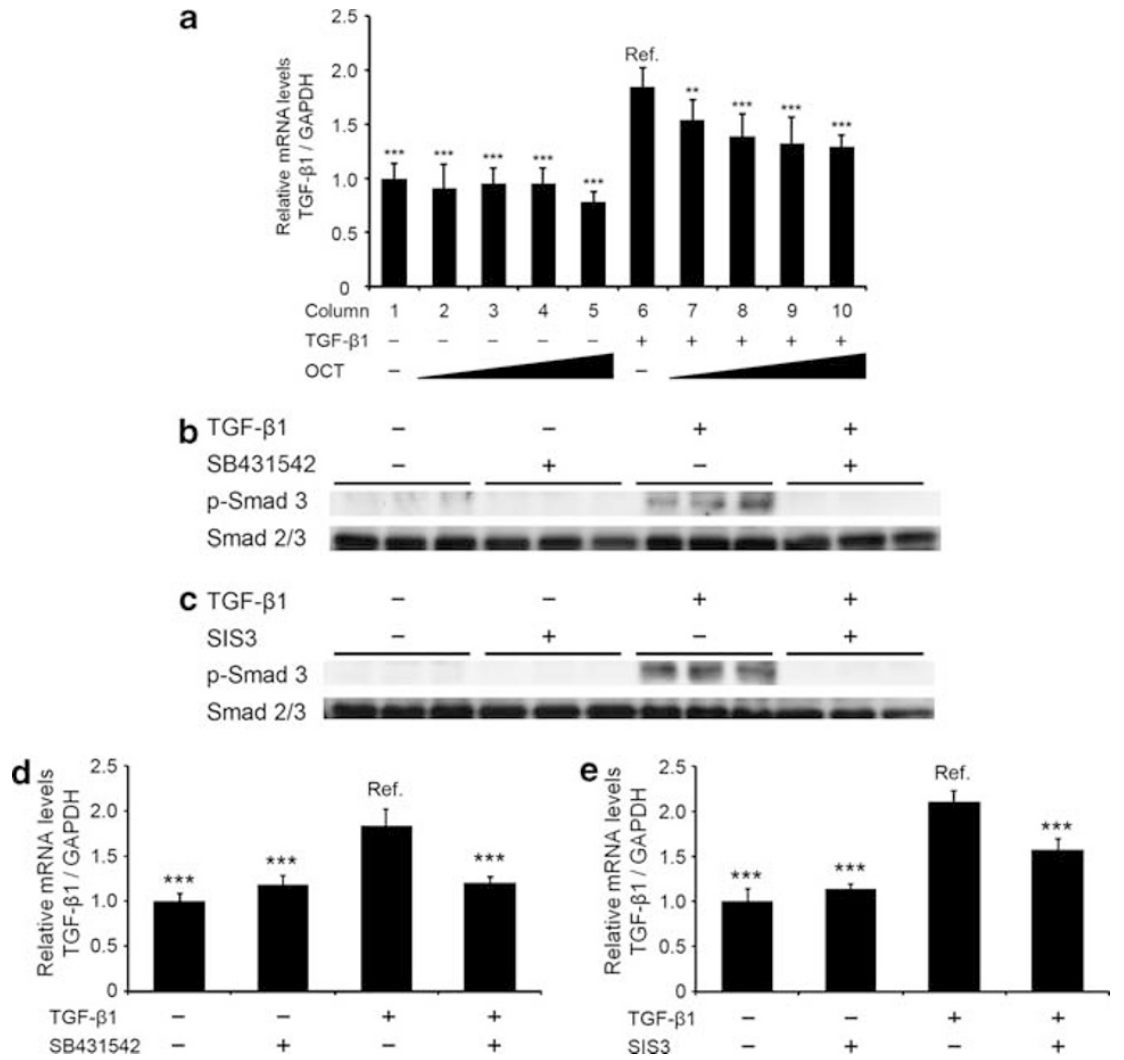

Figure 7 TGF- $\beta 1$ induced its own expression in a pSmad3-dependent manner in cultured NRK-52E cells. (a) Messenger RNA expression levels of TGF- $\beta 1$ were analyzed by real-time PCR. NRK-52E cells were treated in the same way as Figure 6 . The addition of TGF- $\beta 1$ to culture media at a dose of $1.0 \mathrm{ng} / \mathrm{ml}$ induced mRNA for TGF- $\beta 1$ in NRK-52E cells. OCT inhibited TGF- $\beta 1$-induced expression of TGF- $\beta 1$ in a dose-dependent manner ( $n=6$ in each group: ${ }^{* *} P<0.01 ;{ }^{* *} P<0.001$, Dunnett's test). Western blot analyses demonstrated that (b) SB431542, a selective inhibitor of TGF- $\beta 1$ type I receptor, at a dose of $10 \mu \mathrm{m}$, or (c) SIS3, a selective Smad3 inhibitor, at a dose of $2.0 \mu \mathrm{m}$, inhibited the phosphorylation of Smad3 in cultured NRK-52E cells. (d, e) Under these conditions, TGF- $\beta 1$-dependent induction of mRNA for TGF- $\beta 1$ was inhibited $\left(n=4\right.$ in each group: ${ }^{* * *} P<0.001$, Dunnett's test).

causative element, we performed a ChIP assay using the primer set that amplifies the DNA sequence of segment $\mathrm{C}$ (Figure $8 \mathrm{aB}$ arrows and Figure 9a). The ChIP assay revealed that $\mathrm{pSmad} 3$ bound to segment $\mathrm{C}$ under the stimulation of TGF- $\beta 1$ (Figure 9a). Both OCT and SIS3 abrogated the binding (Figure 9a). Although the anti-VDR antibody we used here detected the interaction between VDR and the promoter of CYP24A1, a well-established target gene of vitamin $\mathrm{D}$ signaling, there was no interaction between VDR and segment $\mathrm{C}$ under any of our experimental conditions (Figures $9 \mathrm{a}$ and $\mathrm{b}$ ). This indicated that the inhibition of TGF- $\beta 1$ autoinduction by OCT was not mediated through the direct interaction between liganded VDR and the DNA sequence of segment C. Because immunoprecipitation assays demonstrated that VDR physically interacted with pSmad3 under the stimulation of both TGF- $\beta 1$ and OCT (Figure 9c), we searched for pSmad3-inhibitory molecules that interact with VDR. Western blot analyses revealed that TGF- $\beta 1$ and/ or OCT treatment did not affect the nuclear expression levels of VDR (Figure 9d). TGF- $\beta 1$ increased both the nuclear expression levels of PPM1A, a Smad3 phosphatase, and the interaction levels between VDR and PPM1A (Figures 9d and e). OCT did not affect the nuclear levels of PPM1A nor the interaction levels between VDR and PPM1A (Figures 9d and e). Because VDR and pSmad3 physically interacted with each other under the stimulation of both TGF- $\beta 1$ and OCT, but not under the mono-treatment of TGF- $\beta 1$ or OCT (Figure 9c), the strongest interaction between pSmad 3 and PPM1A was observed under the stimulation of both TGF- $\beta 1$ and OCT (Figure 9e). These findings indicated that OCT ameliorated TIF by inhibiting the pSmad3-TGF- $\beta 1$ vicious circle through the recruitment of the PPM1A/VDR complex to $\mathrm{pS}$ mad3.

\section{DISCUSSION}

In this study, we demonstrated that OCT ameliorates TIF in UUO rats. Although previous studies have suggested that renin suppression is the key mechanism for renoprotection by active vitamin D, OCT did not suppress renin in the kidney. ${ }^{26}$ OCT protected the kidney in UUO rats by abrogating the vicious circle of the pSmad3-TGF- $\beta 1$ by recruiting the PPM1A/VDR complex to pSmad3. Our study 

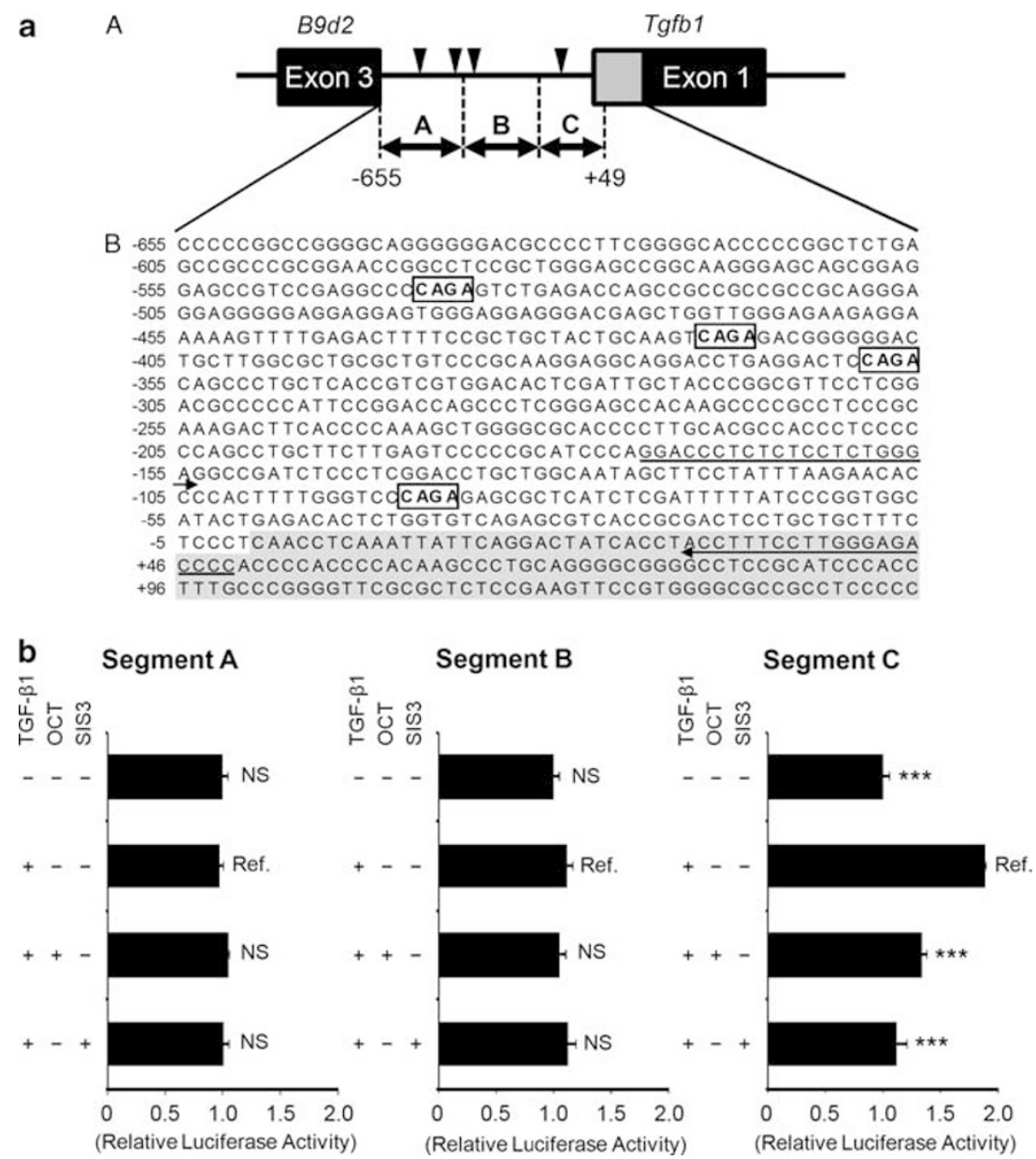

Figure 8 Deletion analysis of the TGF- $\beta 1$ gene promoter revealed that segment $C$ was sufficient to mediate both TGF- $\beta 1$-dependent production of TGF- $\beta 1$ and OCT-dependent suppression of TGF- $\beta 1$. (a) (A) Segments of the rat TGF- $\beta 1$ gene used in the experiments are shown. Black boxes indicate exons. The gray box indicates a $5^{\prime}$ untranslated region (5'UTR) of TGF- $\beta 1$ gene. Arrowheads indicate putative SBEs. (B) The DNA sequence of the rat TGF- $\beta 1$ promoter region ( -655 to $+145 \mathrm{bp}$ ) is shown. Gray background indicates a $5^{\prime}$-UTR of TGF- $\beta 1$. Boxed areas are putative SBE motifs. Arrows indicate the primer sets used for the following ChIP assay in Figure 9. (b) Using NRK-52E cells, responsiveness of each segment was assessed by a luciferase assay system. The value of a vehicle-treated sample was designated as 1.0. Data were representative of at least three independent experiments. Note that segment $C$ was sufficient to mediate both the TGF- $\beta 1$-dependent induction of TGF- $\beta 1$ and the OCT-dependent suppression of TGF- $\beta 1$ induction.

demonstrated the potential of OCT as an inhibitor of the TGF- $\beta 1$ signaling pathway.

The most obvious features of renin transcription are its strong inducibility by cyclic adenosine monophosphate (cAMP). ${ }^{28}$ Several cAMP response elements (CREs) have been identified in the proximal promoter regions of renin genes in various species. ${ }^{28,29}$ Although $1,25(\mathrm{OH})_{2} \mathrm{D}$ suppresses renin transcription by blocking the activity of CRE, OCT did not affect renin expression in the kidney (Figure 3). ${ }^{11}$ It might be due to the unique recruitment of transcriptional coregulators to VDR by OCT ${ }^{30}$ Unlike $1,25(\mathrm{OH})_{2}$ D-bound VDR, OCT-bound VDR does not recruit a family of transcriptional coregulators, such as the steroid receptor coactivator 1 (SRC1), amplified in breast cancer 1 (AIB1), nor the receptor-interacting protein $140 .{ }^{30}$
Because a ligand-dependent strong interaction between nuclear receptors and CREB-binding protein/p300 requires SRC1, the inability of OCT to recruit SRC1 may explain the reason, at least in part, why OCT does not suppress renin. ${ }^{31-33}$

OCT ameliorated TIF by abrogating the TGF- $\beta 1 / \mathrm{Smad} 3$ signaling pathway (Figures 1, 2, and 4-9). On the basis of our results, the underlying mechanism is schematically summarized in Figure 10. In contrast to the kidney of normal control rats (Figure 10a), the kidney of the UUO rats without OCT treatment has activated TGF- $\beta 1 / \mathrm{Smad} 3$ (Figure 10b). TGF- $\beta 1$ elevates its own expression in a pSmad3-dependent manner (Figure 10b). Consistent with our observations, Sato et $a b^{34}$ reported that ligation of the ureter elevates the expression of TGF- $\beta 1$ in wild mice kidney, but not in Smad3 


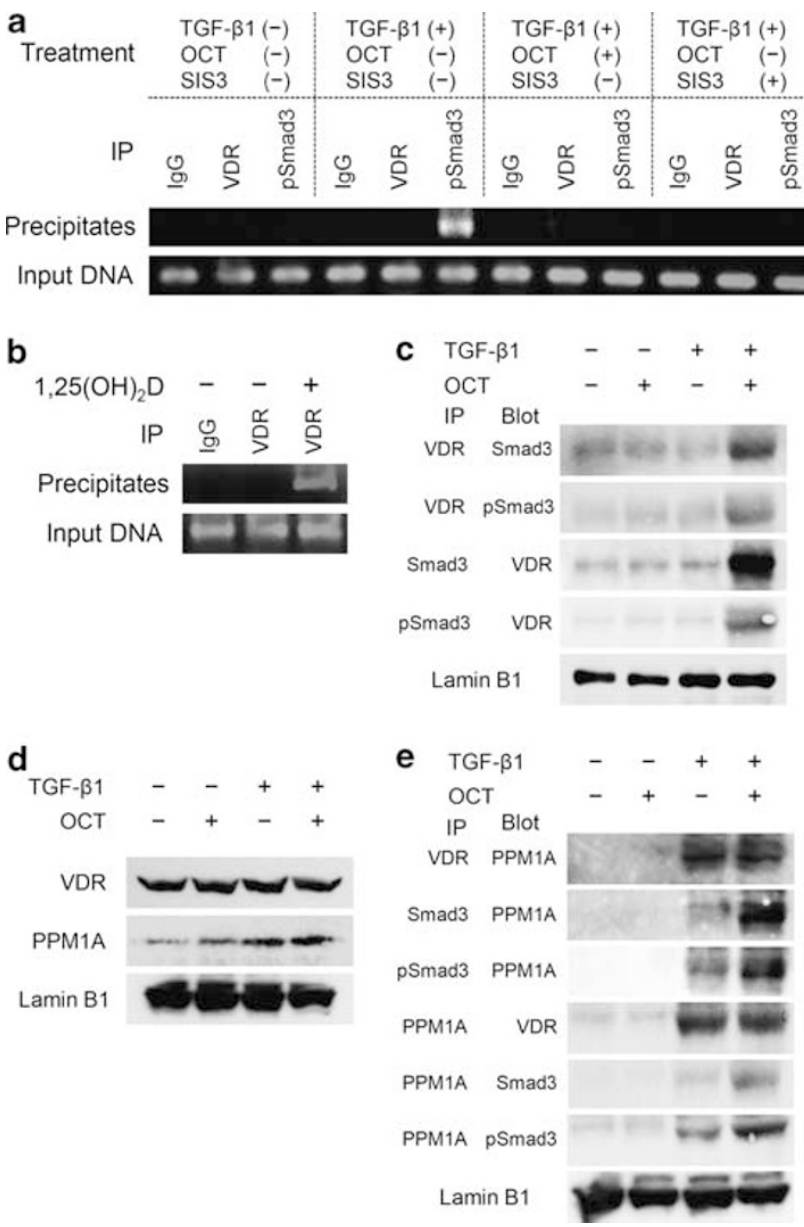

Figure 9 OCT inhibited the binding of pSmad3 to the promoter region of TGF- $\beta 1$ gene by recruiting PPM1A/VDR complex to pSmad3. (a) Using NRK-52E cells, a ChIP assay was performed to detect proteins bound to the TGF- $\beta 1$ promoter segment C (Figure 8A). Phosphorylated Smad3 bound to the promoter under the stimulation of TGF- $\beta 1$. Both OCT and SIS3 inhibited the binding. VDR did not bind to the promoter under any of our examined conditions. (b) The applicability of the anti-VDR antibody we used here to a ChIP assay was confirmed. (c) Nuclear proteins from NRK-52E cells treated with OCT $\left(1.0 \times 10^{-8} \mathrm{M}\right)$, TGF- $\beta 1$ $(1.0 \mathrm{ng} / \mathrm{ml})$, or both, were assessed for endogenous pSmad3/VDR complex formation by immunoprecipitation. (d) Nuclear expression levels of VDR and PPM1A were analyzed by western blotting. The same nuclear protein samples as in Figure $9 \mathrm{C}$ were analyzed. (e) The same nuclear protein samples as in Figure $9 \mathrm{C}$ were assessed for endogenous pSmad3/ PPM1A complex formation by immunoprecipitation. OCT enhanced the interaction between $\mathrm{PSmad} 3$ and PPM1A under the stimulation of TGF- $\beta 1$. Data were representative of at least three independent experiments.

knockout mice kidney. Although TGF- $\beta 1$ increases nuclear levels of PPM1A, the interaction between $\mathrm{pSmad} 3$ and PPM1A is insufficient to attenuate pSmad3 signaling because the PPM1A/VDR complex is not recruited to pSmad3 in the absence of OCT (Figure 10b). Similar to the interaction between $1,25(\mathrm{OH})_{2} \mathrm{D}$-bound VDR and Smad3, OCT-bound VDR physically interacts with pSmad3 (Figure 10c). ${ }^{35}$ This interaction recruits PPM1A to pSmad3, and then inhibits pSmad3-dependent transcription of TGF- $\beta 1$ by dephosphorylating pSmad3 (Figure 10c). All of our findings indicated that OCT blocked the autoinduction of TGF- $\beta 1$ by recruiting the PPM1A/VDR complex to pSmad3.

The property of OCT as an inhibitor of the TGF- $\beta 1$ pathway, but not of RAS, suggests the potential of OCT as an add-on therapy in chronic kidney disease (CKD) patients. It has been well established that the activation of RAS is hazardous, leading to the progression of CKD. ${ }^{36-38}$ Therefore, numerous RAS inhibitors, such as direct renin inhibitor, angiotensin-converting enzyme inhibitors, angiotensin II receptor type 1 blockers, and/or aldosterone blockers, have been administered to patients with CKD. ${ }^{36-38}$ The importance of RAS inhibitors in the treatment of CKD is without doubt, but the high prevalence of CKD in an era of RAS inhibitors indicates that it is necessary to develop new renoprotective strategies with therapeutic mechanisms independent of RAS inhibition. ${ }^{39-41}$ If the main renoprotective mechanism of active vitamin $\mathrm{D}$ was renin suppression, therapeutic potential of active vitamin D would be severely limited, because direct renin inhibitor (aliskiren) is currently available. Here, we demonstrated that OCT is one of the direct inhibitors of the TGF- $\beta 1 / \mathrm{Smad}$ pathway at the transcriptional level. Of note, this TGF- $\beta 1 /$ Smad-suppressive effect of OCT was independent of RAS-inhibition. As aberrant expression of TGF- $\beta 1$ has been revealed in virtually all CKD patients, an inhibitor for the TGF- $\beta 1 /$ Smad signaling pathway seems to be a promising agent. ${ }^{14}$ Although Tan et $a l^{23,25}$ reported that another lesscalcemic analog, paricalcitol, suppresses both renal renin and TGF- $\beta 1$ levels in UUO mice, the mechanism how paricalcitol suppresses TGF- $\beta 1$ is currently unknown. Because the activation of RAS can induce TGF- $\beta 1$ expression, TGF- $\beta 1$ suppressive effect of paricalcitol might be derived merely from the suppression of RAS. ${ }^{42,43}$ Further studies are required to know whether paricalcitol has direct TGF- $\beta 1$ suppressive mechanism similar to OCT.

Although we have demonstrated that OCT ameliorates TIF by abrogating the vicious circle of the pSmad3-TGF- $\beta 1$, there remain several limitations in the current study. First, several findings in our study are based on in vitro examinations, but not on in vivo results. Second, we cannot rule out the possibility that several other mechanisms participated in the OCT-dependent renoprotection. Indeed, we found that OCT suppresses inflammatory parameters in the obstructed kidneys (Supplementary Figure 1). Third, we demonstrated the therapeutic effects of OCT only using a short-term UUO model. Therefore, long-term effects and/or therapeutic effects of OCT on the other TIF models remain obscure. Further studies are required to address these issues.

In conclusion, OCT ameliorated TIF by abrogating the pSmad3-dependent autoinduction of TGF- $\beta 1$. OCT dephosphorylated $\mathrm{pSmad} 3$ by recruiting the PPM1A/VDR complex to $\mathrm{pSmad} 3$. Our findings provide a novel approach to inhibit the TGF- $\beta /$ Smad3 pathway. 

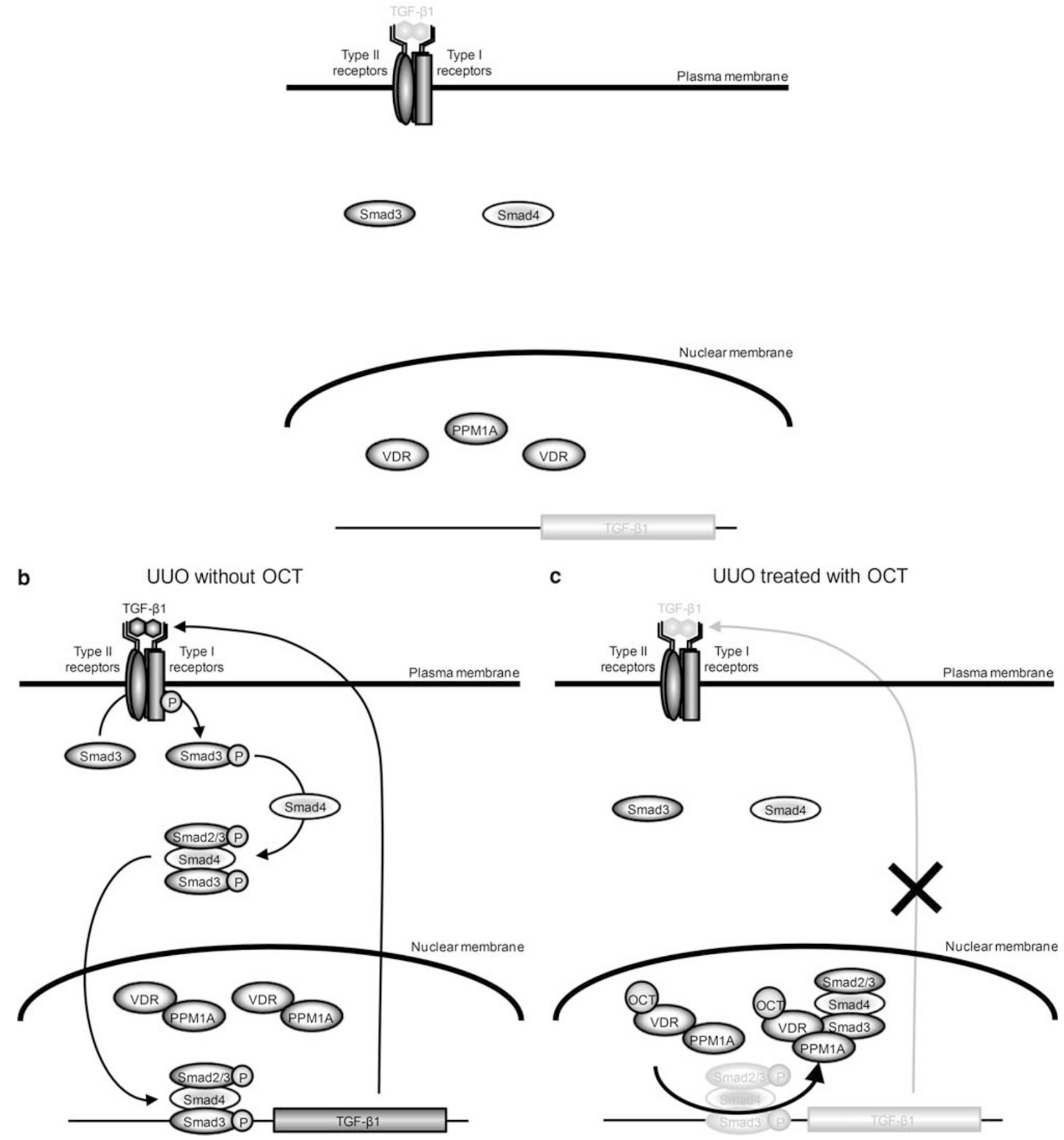

Figure 10 Experimental results are schematically summarized. (a) The TGF- $\beta 1 / \mathrm{Smad} 3$ signaling pathway is not activated in the kidneys of normal control rats. (b) In the kidneys of UUO rats without OCT treatment, TGF- $\beta 1$ binds to its receptors and activates its downstream components, Smad proteins. Phosphorylated Smad3 binds to the promoter region of the TGF- $\beta 1$ gene and promotes the transcription of TGF- $\beta 1$. The TGF- $\beta 1 / \mathrm{Smad} 3$ system forms a vicious circle. Upregulated nuclear PPM1A, under the stimulation of TGF- $\beta 1$, physically interacted with VDR, but the PPM1A/VDR complex is not recruited to pSmad3 in the absence of OCT. (c) OCT suppresses the expression of TGF- $\beta 1$. The absence of pSmad3 in the promoter of the TGF- $\beta 1$ gene under OCT-treated conditions indicates that OCT suppresses TGF- $\beta 1$ by inhibiting the pSmad3-dependent transcription of TGF- $\beta 1$. OCT induces the physical interaction between the PPM1A/VDR complex and pSmad3. As a result of dephosphorylation of pSmad3 by PPM1A, the vicious circle is inhibited. 
Supplementary Information accompanies the paper on the Laboratory Investigation website (http://www.laboratoryinvestigation.org)

\section{ACKNOWLEDGEMENTS}

We thank Naoko Horimoto for her technical assistance. This research was supported by a grant-in-aid for Scientific Research from the Ministry of Education, Culture, Sports, Science and Technology, Japan (no. 20790593 to IM) and Chugai Pharmaceutical (to IM).

\section{DISCLOSURE/CONFLICT OF INTEREST}

$\mathrm{MH}$ is an employee of Chugai Pharmaceutical. TH belongs to a Department that was funded partly with Chugai Pharmaceutical. The other authors declare no conflict of interest.

1. Zhang Z, Zhang $Y$, Ning G, et al. Combination therapy with AT1 blocker and vitamin $\mathrm{D}$ analog markedly ameliorates diabetic nephropathy: blockade of compensatory renin increase. Proc Natl Acad Sci U S A 2008;105:15896-15901.

2. Bohle A, Mackensen-Haen $\mathrm{S}$, von Gise $H$. Significance of tubulointerstitial changes in the renal cortex for the excretory function and concentration ability of the kidney: a morphometric contribution. Am J Nephrol 1987;7:421-433.

3. Hewitson TD. Renal tubulointerstitial fibrosis: common but never simple. Am J Physiol Renal Physiol 2009;296:F1239-F1244.

4. Chevalier RL, Forbes MS, Thornhill BA. Ureteral obstruction as a model of renal interstitial fibrosis and obstructive nephropathy. Kidney Int 2009;75:1145-1152.

5. Zeisberg $M$, Neilson EG. Mechanisms of tubulointerstitial fibrosis. J Am Soc Nephrol 2010;21:1819-1834.

6. Zhang Y, Kong J, Deb DK, et al. Vitamin D receptor attenuates renal fibrosis by suppressing the renin-angiotensin system. J Am Soc Nephrol 2010;21:966-973.

7. LT Jr SKEGGS, JR KAHN, K Lentz, et al. The preparation, purification, and amino acid sequence of a polypeptide renin substrate. J Exp Med 1957;106:439-453.

8. Fisher ND, Hollenberg NK. Renin inhibition: what are the therapeutic opportunities?. J Am Soc Nephrol 2005;16:592-599.

9. Li YC, Kong J, Wei M, et al. 1,25-Dihydroxyvitamin $D(3)$ is a negative endocrine regulator of the renin-angiotensin system. J Clin Invest 2002;110:229-238.

10. Kong J, Qiao G, Zhang Z, et al. Targeted vitamin D receptor expression in juxtaglomerular cells suppresses renin expression independent of parathyroid hormone and calcium. Kidney Int 2008;74:1577-1581.

11. Yuan W, Pan W, Kong J, et al. 1,25-dihydroxyvitamin D3 suppresses renin gene transcription by blocking the activity of the cyclic AMP response element in the renin gene promoter. J Biol Chem 2007:282:29821-29830.

12. Zhou C, Lu F, Cao K, et al. Calcium-independent and 1,25(OH)2D3dependent regulation of the renin-angiotensin system in 1alphahydroxylase knockout mice. Kidney Int 2008;74:170-179.

13. Freundlich $M$, Quiroz $Y$, Zhang $Z$, et al. Suppression of reninangiotensin gene expression in the kidney by paricalcitol. Kidney Int 2008;74:1394-1402.

14. Garcia-Sanchez O, Lopez-Hernandez FJ, Lopez-Novoa JM. An integrative view on the role of TGF-beta in the progressive tubular deletion associated with chronic kidney disease. Kidney Int 2010;77:950-955.

15. Wolf $G$. Renal injury due to renin-angiotensin-aldosterone system activation of the transforming growth factor-beta pathway. Kidney Int 2006;70:1914-1919.

16. Schmierer B, Hill CS. TGFbeta-SMAD signal transduction: molecular specificity and functional flexibility. Nat Rev Mol Cell Biol 2007;8: 970-982.

17. Lin $X$, Duan $X$, Liang YY, et al. PPM 1 A functions as a Smad phosphatase to terminate TGFbeta signaling. Cell 2006;125:915-928.

18. Jones G, Strugnell SA, DeLuca HF. Current understanding of the molecular actions of vitamin D. Physiol Rev 1998;78:1193-1231.

19. Matsui I, Hamano T, Tomida K, et al. Active vitamin D and its analogue, 22-oxacalcitriol, ameliorate puromycin aminonucleoside-induced nephrosis in rats. Nephrol Dial Transplant 2009;24:2354-2361.
20. Nishiyama A, Seth DM, Navar LG. Renal interstitial fluid concentrations of angiotensins I and II in anesthetized rats. Hypertension 2002;39: 129-134.

21. Suzuki A, Ito T, Imai E, et al. Retinoids regulate the repairing process of the podocytes in puromycin aminonucleoside-induced nephrotic rats. J Am Soc Nephrol 2003;14:981-991.

22. Matsui I, Ito $\mathrm{T}$, Kurihara $\mathrm{H}$, et al. Snail, a transcriptional regulator, represses nephrin expression in glomerular epithelial cells of nephrotic rats. Lab Invest 2007;87:273-283.

23. Tan $\mathrm{X}, \mathrm{Li} \mathrm{Y}$, Liu Y. Paricalcitol attenuates renal interstitial fibrosis in obstructive nephropathy. J Am Soc Nephrol 2006;17:3382-3393.

24. Matsui I, Hamano T, Mikami S, et al. Fully phosphorylated fetuin-A forms a mineral complex in the serum of rats with adenine-induced renal failure. Kidney Int 2009;75:915-928.

25. Tan X, He W, Liu Y. Combination therapy with paricalcitol and trandolapril reduces renal fibrosis in obstructive nephropathy. Kidney Int 2009;76:1248-1257.

26. Li YC. Renoprotective effects of vitamin D analogs. Kidney Int 2010;78:134-139.

27. Deb DK, Sun T, Wong KE, et al. Combined vitamin D analog and AT1 receptor antagonist synergistically block the development of kidney disease in a model of type 2 diabetes. Kidney Int 2010;77:1000-1009.

28. Bader M, Ganten D. Regulation of renin: new evidence from cultured cells and genetically modified mice. J Mol Med 2000;78:130-139.

29. Tamura K, Umemura S, Fukamizu A, et al. Recent advances in the study of renin and angiotensinogen genes: from molecules to the whole body. Hypertens Res 1995;18:7-18.

30. Takeyama K, Masuhiro $\mathrm{Y}$, Fuse $\mathrm{H}$, et al. Selective interaction of vitamin $\mathrm{D}$ receptor with transcriptional coactivators by a vitamin $\mathrm{D}$ analog. Mol Cell Biol 1999;19:1049-1055.

31. Kraus WL, Manning ET, Kadonaga JT. Biochemical analysis of distinct activation functions in p300 that enhance transcription initiation with chromatin templates. Mol Cell Biol 1999;19:8123-8135.

32. Li J, O'Malley BW, Wong J. p300 requires its histone acetyltransferase activity and SRC-1 interaction domain to facilitate thyroid hormone receptor activation in chromatin. Mol Cell Biol 2000;20:2031-2042.

33. Sheppard HM, Harries JC, Hussain S, et al. Analysis of the steroid receptor coactivator 1 (SRC1)-CREB binding protein interaction interface and its importance for the function of SRC1. Mol Cell Biol 2001;21:39-50

34. Sato M, Muragaki Y, Saika S, et al. Targeted disruption of TGF-beta1/ Smad3 signaling protects against renal tubulointerstitial fibrosis induced by unilateral ureteral obstruction. J Clin Invest 2003;112: 1486-1494.

35. Yanagisawa J, Yanagi $Y$, Masuhiro $Y$, et al. Convergence of transforming growth factor-beta and vitamin $D$ signaling pathways on SMAD transcriptional coactivators. Science 1999;283:1317-1321.

36. Locatelli F, Del Vecchio L, Cavalli A. Inhibition of the renin-angiotensin system in chronic kidney disease: a critical look to single and dual blockade. Nephron Clin Pract 2009;113:c286-c293.

37. Lattanzio MR, Weir MR. Does blockade of the renin-angiotensinaldosterone system slow progression of all forms of kidney disease? Curr Hypertens Rep 2010;12:369-377.

38. Turgut F, Balogun RA, Abdel-Rahman EM. Renin-angiotensinaldosterone system blockade effects on the kidney in the elderly: benefits and limitations. Clin J Am Soc Nephrol 2010;5:1330-1339.

39. Clark LE, Khan I. Outcomes in CKD: what we know and what we need to know. Nephron Clin Pract 2010;114:c95-102.

40. Hedayati SS, Finkelstein FO. Epidemiology, diagnosis, and management of depression in patients with CKD. Am J Kidney Dis 2009;54: 741-752.

41. Anothaisintawee $T$, Rattanasiri S, Ingsathit A, et al. Prevalence of chronic kidney disease: a systematic review and meta-analysis. Clin Nephrol 2009;71:244-254.

42. Yang $F$, Chung AC, Huang XR, et al. Angiotensin II induces connective tissue growth factor and collagen I expression via transforming growth factor-beta-dependent and -independent Smad pathways: the role of Smad3. Hypertension 2009;54:877-884.

43. Huang J, Matavelli LC, Siragy HM. Renal (pro)renin receptor contributes to development of diabetic kidney disease through transforming growth factor-beta1-connective tissue growth factor signalling cascade. Clin Exp Pharmacol Physiol 2011;38:215-221. 